\title{
ATIVIDADE DA PECTINAMETILESTERASE E SUA RELAÇÃO COM A PERDA DE FIRMEZA DA POLPA DE MAMÃO CV. SUNRISE SOLO E TAINUNG ${ }^{1}$
}

\author{
RENATA VENTURIM FONTES ${ }^{2}$, MIRELLA PUPO SANTOS ${ }^{3}$, ANTELMO RALPH FALQUETO $^{4}$, DIOLINA MOURA SILVA $^{5}$
}

RESUMO - O objetivo deste trabalho foi avaliar a atividade da pectinametilesterase (PME) em mamão (Carica papaya L.), cv. Sunrise Solo e Tainung, e relacionar suas alterações com a perda de firmeza da polpa durante o amadurecimento. Os frutos foram coletados diariamente em uma lavoura comercial em Aracruz - ES, e armazenados sob temperatura ambiente (aproximadamente, $25^{\circ} \mathrm{C}$ ) até o período das análises. A perda da firmeza da polpa dos frutos das cultivares iniciou-se no $4^{\circ}$ dia após a colheita (DAC); entretanto, a cv. Sunrise Solo apresentou uma redução mais acentuada em relação à cv. Tainung. A atividade da PME na cv. Sunrise Solo foi alta no 1 $\mathrm{DAC}$ e reduziu gradativamente até o $4^{\circ} \mathrm{DAC}$, quando atingiu seu menor valor. No 5o DAC, a atividade aumentou, permanecendo praticamente inalterada até o $8^{\circ} \mathrm{DAC}$. Na cv. Tainung, a atividade aumentou até o $3^{\circ} \mathrm{DAC}$ e decresceu no $4^{\circ} \mathrm{DAC}$. No $5^{\circ} \mathrm{DAC}$, sua atividade aumentou novamente, atingindo seu maior valor no $6^{\circ}$ DAC. A partir daí, a atividade da enzima reduziu-se significativamente, mantendo o mesmo valor até o último dia de análise ( $\left.8^{\circ} \mathrm{DAC}\right)$. O coeficiente de correlação obtido entre a atividade da PME e a firmeza da polpa dos frutos da cv. Sunrise Solo, após o $4^{\circ} \mathrm{DAC}$, foi de $\mathrm{R}=-0,84$, indicando que, durante esse período, a firmeza da polpa dos frutos diminuiu à medida que a atividade da PME aumentou. Por outro lado, não houve correlação significativa entre essas duas características na cv. Tainung.

Termos para indexação: pós-colheita, pectinametilesterase, firmeza, mamão, polpa.

\section{THE PECTINMETHYLESTERASE ACTIVITY AND ITS RELATION WITH THE LOSS OF FIRMNESS OF THE PULP IN PAPAYA FRUITS cv. SUNRISE SOLO AND TAINUNG}

\begin{abstract}
The objective of this work was to evaluate the pectinmethylesterase (PME) activity in papaya (Carica papaya L.) fruits cv. Sunrise Solo and Tainung, and to correlate its changes with the pulp firmness loss during fruit ripening. Fruits were collected daily from a commercial farm localized in Aracruz - ES, and stored under room temperature (approximately $25^{\circ} \mathrm{C}$ ) until the period of analysis. The pulp firmness loss of the fruits in both cultivars began at the 4th day after harvest (DAH); however, the cv. Sunrise Solo presented highest reduction than the cv. Tainung. The PME activity of cv. Sunrise Solo was higher at the 1st DAH, and decreased slowly at the 4th DAH, reaching its smallest value. At the 5th DAH the activity increased, remaining practically the same at the 8th DAH. In the cv. Tainung, the PME activity increased until the 3rd DAH and decreased at the 4th DAH. In the 5th DAH, its activity increased again reaching its higher value at the 6th DAH. From this on, the enzyme activity decreased significantly, maintaining the same value until the last day of analysis (8th DAH). The correlation coefficient obtained between the PME activity and the pulp firmness in the cv. Sunrise Solo after the 4 th $D A H$ was $R=-0,84$, indicating that during this period, the pulp firmness of the fruits decreased when the PME activity increased. On the other hand, there was no significant correlation between these two characteristics in the cv. Tainung.
\end{abstract}

Index terms: post harvest, pectinmethylesterase, firmness, papaya, pulp.

\section{INTRODUÇÃO}

O mamão (Carica papaya L.) é um fruto climatérico cujas transformações resultantes do amadurecimento ocorrem rapidamente após a colheita do fruto fisiologicamente maduro e são desencadeadas pela produção do etileno e aumento da taxa respiratória. Isso o caracteriza como um fruto bastante perecível na fase pós-colheita. Segundo Jacomino et al. (2002), os principais fatores que depreciam a qualidade dos frutos de mamão na pós-colheita são o rápido amolecimento e a elevada incidência de podridões. Considerando essa alta perecibilidade, é de fundamental importância controlar o processo de amadurecimento dos frutos.

$\mathrm{O}$ amadurecimento dos frutos ocorre mediante diversas reações, tanto de síntese como de degradação, culminando na perda de firmeza da polpa, parâmetro considerado como um dos atributos de qualidade. Dentre as causas principais da perda da firmeza da polpa do mamão, estão a degradação de protopectina da lamela média e da parede celular primária, o aumento da pectina solúvel e a perda de açúcares neutros não-celulósicos (Jacomino et al., 2002). Essas alterações bioquímicas resultam, provavelmente, de mudanças na atividade de enzimas hidrolíticas,

${ }^{1}$ (Trabalho 062-07). Recebido em: 16-03-2007. Aceito para publicação em: 07-01-2008. Parte da Dissertação de Mestrado do primeiro autor. Apoio financeiro: CAPES, Banco do Nordeste e Brapex.

${ }^{2}$ Bióloga, MSc. em Biologia Vegetal, PPGBV/UFES, Doutoranda em Produção Vegetal, UENF, rvfontes@yahoo.com.br

${ }^{3}$ Bióloga, MSc em Biologia Vegetal, PPGBV/UFES, Doutoranda em Genética e Melhoramento de Plantas, UENF, mirellapupo@yahoo.com.br

${ }^{4}$ Biólogo, MSc. em Biologia Vegetal, PPGBV/UFES, Doutorando em Fisiologia Vegetal, UFPel, antelmofalqueto@yahoo.com.br

${ }^{5}$ Prof. Associado, DSc. Em Fisiologia Vegetal, Programa de pós-Graduação em Biologia Vegetal, Universidade Federal do Espírito Santo, Av. Fernando Ferrari, 514 - Goiabeiras - Vitória - ES. CEP 29075910, biovegetal@terra.com.br 
como as poligalacturonase, pectinametilesterase, $\beta$-galactosidase e celulases presentes nas células, juntamente com a perda de água (Abu-Goukh \& Bashir, 2003; Owino et al., 2004).

O resultado de alguns trabalhos aponta a degradação enzimática da parede celular determinante para a perda de firmeza da polpa do mamão. Segundo Camargo et al. (2000), a perda de firmeza da polpa durante o amadurecimento é atribuída à ação de pectinases presentes na parede celular: a pectinametilesterase (PME) e a poligalacturonase (PG). De acordo com Abu-Sarra \& Abu-Goukh (1992), a PME catalisa a desesterificação dos resíduos de galacturonosil presentes no polímero homogalacturonano de ácido galacturônico, no qual o grupo carboxílico se encontra metilesterificado, atuando nos finais redutores e no interior das cadeias pécticas com alto grau de esterificação, reduzindo seu peso. Já segundo Evangelista et al. (2000), a PG, encontrada na maioria dos frutos, catalisa a hidrólise das ligações $\beta-1,4$ entre os resíduos de ácido galacturônico no interior da cadeia de pectina.

Bicalho et al. (2000) sugeriram que a atividade da PME preceda a atividade da PG, uma vez que a PME atua na desmetilação do poliuronídeo. Assim, a PG teria maior afinidade pelo substrato linear desmetilado, após a atuação da PME. Entretanto, Manrique \& Lajolo (2004) propuseram a participação da PME diretamente no processo de amolecimento dos frutos, desesterificando o polímero de ácido galacturônico (pectina), enquanto a PG catalisa a hidrólise das ligações $\beta-1,4$ entre os resíduos de ácido galacturônico no interior da cadeia de pectina.

Com base nessas informações, o objetivo do trabalho foi determinar a atividade da PME, durante o período de póscolheita do mamão (Carica papaya L.) cvs. Tainung e Sunrise Solo, relacionando sua atividade com a perda de firmeza da polpa dos frutos.

\section{MATERIAL E MÉTODOS}

Frutos - Mamões das cv. Sunrise Solo (grupo Solo) e Tainung (grupo Formosa) foram coletados da lavoura comercial fornecedora da Agra Pex Brazilian Papaya, localizada no município de Aracruz - ES, latitude 1949'13 sul, longitude $40^{\circ} 16^{\prime} 24$ oeste e altitude de 60 metros (IBGE, 2005). Para cada cultivar, foram colhidos 20 frutos no estádio 2 de amadurecimento (Souza, 1998), quando apresentavam casca de coloração verde-clara e estrias longitudinais, partindo da base do fruto até o pedúnculo. Esse ponto de colheita é o mais utilizado para o mercado externo. Os frutos selecionados foram acondicionados em caixas de mercado externo e transportados para o laboratório de Ecofisiologia do Depto. de Ciências Biológicas da Universidade Federal do Espírito Santo, onde foram lavados em solução de hipoclorito de sódio a $5 \%$ para desinfecção. Os frutos permaneceram à temperatura ambiente (aproximadamente, $25^{\circ} \mathrm{C}$ ) até o momento das análises.

Quantificação da firmeza - A quantificação da firmeza dos frutos foi feita do $3^{\circ}$ ao $8^{\circ}$ DAC com a utilização de um penetrômetro marca EFFEGI. Oito frutos escolhidos aleatoriamente tiveram a casca removida e, na região equatorial da polpa, foram feitas as medidas de firmeza em quatro pontos eqüidistantes. Os resultados, correspondentes à média das quatro medições, foram expressos em $\mathrm{kgf} / \mathrm{cm}^{2}$.

Obtenção das amostras - A obtenção das amostras para as análises da atividade da PME (EC 3.1.1.11) deu-se nos mesmos frutos utilizados para a determinação da firmeza da polpa. Depois de retiradas, as amostras foram congeladas em nitrogênio líquido e mantidas em freezer $\left(-20^{\circ} \mathrm{C}\right)$ até a determinação da atividade enzimática.

Preparação do extrato da PME - A preparação do extrato da polpa foi feita de acordo com Hagerman \& Austin (1986). Amostras de $5 \mathrm{~g}$ de polpa de mamão foram homogeneizadas em $40 \mathrm{~mL}$ de $\mathrm{NaCl} 1,0 \mathrm{M}(\mathrm{pH} 7,5)$ e $40 \mathrm{~mL}$ da suspensão de polivinilpolipirrolidona insolúvel $(1 \mathrm{~g} / 100 \mathrm{~mL})$. O extrato foi centrifugado a $15.000 \mathrm{~g}$ durante 30 minutos em centrífuga refrigerada a $-4{ }^{\circ} \mathrm{C}$ e, no sobrenadante obtido, quantificou-se a atividade da PME logo após ajustar o $\mathrm{pH}$ para 7,5.

Ensaio da atividade da PME - A atividade da PME foi determinada pelo método fotocolorimétrico descrito por Hagerman \& Austin (1986). Esse método baseia-se na mudança de cor do azul de bromotimol (indicador com faixa de viragem entre 6,0 - 7,6) devido à modificação do $\mathrm{pH}$ do meio de reação em conseqüência da hidrólise enzimática da ligação éster da pectina (substrato), a qual expõe grupos carboxílicos. Como substrato, utilizou-se mistura de pectina cítrica $(25 \mathrm{~g} / 100 \mathrm{~mL})$, em água destilada, com azul de bromotimol $(1 \mathrm{~g} / 100 \mathrm{~mL})$ em tampão fosfato de potássio $3 \mathrm{mM}, \mathrm{pH} 7,5$. O pH de todas as soluções foi ajustado para 7,5 com solução de $\mathrm{NaOH}$. Para a análise, foi misturado 0,4 $\mathrm{mL}$ do extrato enzimático a $1,0 \mathrm{~mL}$ da mistura de pectina e azul de bromotimol (para cada $1,0 \mathrm{~mL}$ de pectina, usar $75 \mu \mathrm{L}$ de azul de bromotimol), e a variação de absorbância a $620 \mathrm{~nm}$ foi monitorada durante 2 minutos, com leituras a intervalos de 5 segundos em espectrofotômetro UV/Vis (FEMTO, Mod. 700 plus). Para o cálculo da atividade da PME, foi utilizada uma curva-padrão de ácido galacturônico. A atividade da PME foi expressa em $\mu$ mol de ácido galacturônico liberado por miligrama de proteína por minuto.

Determinação do conteúdo de proteína - Para se obter a atividade específica da enzima PME, o conteúdo protéico do extrato foi determinado por método fotocolorimétrico (Lowry et al., 1951). Uma alíquota da amostra diluída com água, para um volume de $500 \mu \mathrm{L}$, foi acrescida de $5 \mathrm{~mL}$ de reagente de cobre [solução de tartarato de sódio e potássio $(2 \mathrm{~g} / 100 \mathrm{~mL})$, sulfato de cobre ( $2 \mathrm{~g} / 100 \mathrm{~mL})$, carbonato de sódio $(3 \mathrm{~g} / 100 \mathrm{~mL}$ de $\mathrm{NaOH}, 1 \mathrm{M})$ na relação 1:1:48]. Após 10 minutos de repouso, 0,5 $\mathrm{mL}$ de reagente de Folin (1:2) foram adicionados sob agitação, e a leitura da absorbância, a $660 \mathrm{~nm}$, foi feita após 10 minutos. A concentração protéica da amostra foi determinada utilizando a curva-padrão de soro albumina bovina.

Análise estatística - Os resultados foram avaliados de acordo com o delineamento em blocos, com oito repetições diárias de medidas de firmeza e de determinação da atividade da PME. Para determinar as relações e comparações entre os dados, foram realizadas análises de correlação e regressão (Lapponi, 2000).

\section{RESULTADOS E DISCUSSÃO}

A evolução da redução da firmeza da polpa dos mamões 
(cvs. Sunrise Solo e Tainung), durante o período de amadurecimento dos frutos, é apresentada na Figura 1. Em ambas as cultivares, a perda de firmeza teve início no $4^{\circ} \mathrm{DAC}$, porém observou-se que a cv. Sunrise Solo apresentou redução mais acentuada do que a cv. Tainung. Resultados semelhantes foram encontrados por Lazan et al. (1995), trabalhando com a cv. Eksotika. O padrão apresentado pelos frutos climatéricos durante o processo de amadurecimento pode ser bem variável. Por exemplo, frutos de durião (Durio zibethinus Murray) amolecem no $4^{\circ}$ DAC (Imsabai et al., 2002), os de goiaba (Psidium guajava L.) começam a amolecer no $10^{\circ}$ DAC (Carvalho et al., 2001), enquanto os de carambola (Averrhoa carambola L.) apresentam o início do amolecimento da polpa somente após 25 DAC (Ali et al., 2004b). Assim, frutos climatéricos comercializáveis, como o mamão, que é caracterizado pela alta perecebilidade e curta vidade-prateleira, necessitam de estudos relacionados ao controle do seu processo de amadurecimento.

A Figura 2 mostra os perfis de atividade da PME nas duas cultivares. Na cv. Sunrise Solo, a atividade da PME no $1^{\circ}$ DAC foi alta e reduziu gradativamente até o $4^{\circ}$ dia, quando atingiu seu menor valor. No 5 DAC, a atividade aumentou, permanecendo praticamente inalterada até o $8^{\circ} \mathrm{DAC}$. Na cv. Tainung, a atividade da PME aumentou até o $3^{\circ}$ DAC e logo depois, no $4^{\circ}$ dia, diminuiu. No $5^{\circ}$ dia, sua atividade aumentou novamente atingindo seu maior valor no $6^{\circ}$ DAC. A partir daí, a atividade da enzima reduziu-se significativamente, permanecendo com o mesmo valor até o último dia de análise ( $\left.8^{\circ} \mathrm{DAC}\right)$. Esses resultados concordam com os obtidos por Bicalho et al. (2000) em mamões da cv. Improved Sunrise Solo 72/12. Os autores também observaram aumento da atividade da PME no decorrer do período de pós-colheita, declinando gradativamente até o final do amadurecimento. Entretanto, a atividade dessa enzima apresenta comportamento antagônico aos observados no presente estudo. Em mamões da cv. Eksotika, a atividade da PME aumenta gradativamente durante o amadurecimento do fruto (Lazan et al., 1995).

A atividade total da PME pode diminuir, permanecer constante ou aumentar durante a maturação, dependendo do fruto e do método de extração para análise (Lima et al., 2006). Conforme Ali et al. (2004a), as mudanças são ainda mais complexas devido à presença de isoformas ou inibidores enzimáticos. A importância da PME no amaciamento dos frutos é ampliada, quando se considera que essa enzima pode contribuir direta ou indiretamente para a ação de outras, ao criar um ambiente iônico adequado ou, possivelmente, ao modificar a porosidade da parede celular, favorecendo, dessa forma, o acesso de outras enzimas aos seus substratos potenciais. Em mamões, a atividade da PME eleva-se com o amadurecimento, e esse aumento é acompanhado pela elevação da atividade da $\mathrm{PG}$ e redução na firmeza da polpa (Lourenço \& Catutani, 1984; Lazan et al., 1995). Assim, a atividade da PME facilitaria a atuação da PG, que participa diretamente do processo de amadurecimento dos frutos (Bicalho et al., 2000). De acordo com Manrique \& Lajolo (2004), a PME participa do processo de amolecimento dos frutos, desesterificando o polímero de ácido galacturônico (pectina), enquanto a PG catalisa a hidrólise das ligações $\beta-1,4$ entre os resíduos de ácido galacturônico no interior da cadeia de pectina.

Ali et al. (2004b) constataram que o início da perda da firmeza dos frutos de carambola (Averrhoa carambola L.) acompanhou o aumento da atividade da PME. Essa mesma constatação foi feita por Ali et al. (2004a) durante o amadurecimento de frutos de goiaba (Psidium guajava L.), banana (Musa acuminata, grupo AA, família Musaceae), carambola (Averrhoa carambola L.) e mamão. No presente estudo, o coeficiente de correlação obtido entre atividade da PME e firmeza da polpa nos frutos da cv. Sunrise Solo, a partir $4^{\circ} \mathrm{DAC}$, foi de $\mathrm{R}$ $=-0,84$, indicando que, nesse período, a firmeza da polpa decresceu à medida que a atividade da PME aumentou (Figura 3A). Entretanto, para a cv. Tainung, não foi obtida nenhuma correlação direta significativa entre essas duas características (Figura 3B). Provavelmente, como resultado da atividade da PME, seria disponibilizado o substrato (ácido poligalacturônico desmetilado) para a PG. Em razão da complexidade da estrutura da parede celular, é improvável que uma enzima, em particular, seja capaz de modificá-la significativamente e responder pelo amaciamento da polpa do fruto (Ali et al., 2004a). Para promover mudanças texturais relevantes, uma ação coletiva e sinergística de várias enzimas seria necessária (Giovannoni, 2001; Ali et al., 2004a; Mwaniki et al., 2005). Além disso, apesar da grande importância da atividade das hidrolases da parede celular para as modificações na textura, associadas ao amadurecimento, outros agentes, como, por exemplo, as expansinas (proteínas nãoenzimáticas), também contribuem para o processo (Giovannoni, 2001).

Os resultados obtidos fornecem subsídios que sugerem a continuidade das pesquisas visando a desvendar a ação conjunta das enzimas envolvidas na degradação da parede celular da polpa de frutos comercializáveis in natura, como os das cvs. Sunrise Solo e Tainung.

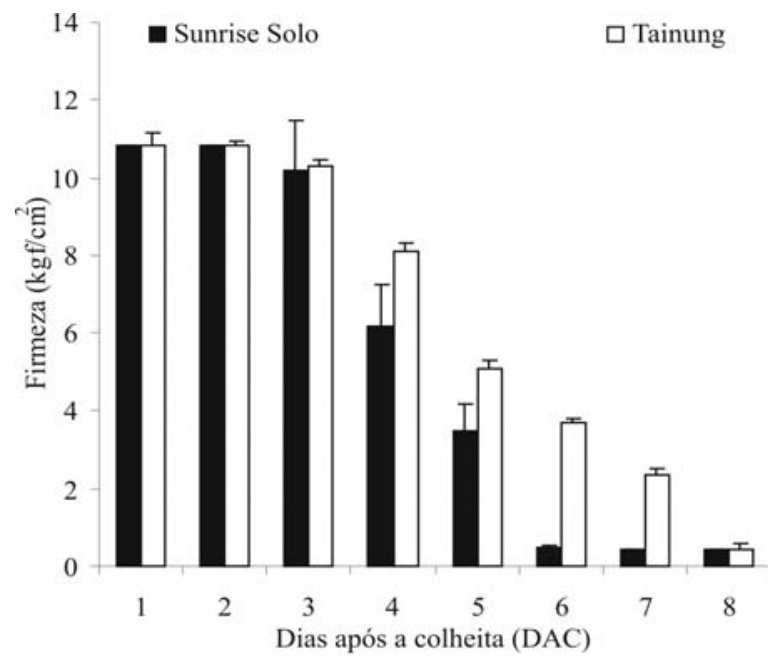

FIGURA 1 - Firmeza da polpa de mamões (Carica papaya L.) cvs. Sunrise Solo e Tainung durante o período de amadurecimento dos frutos. As barras nas colunas representam o erro-padrão. 


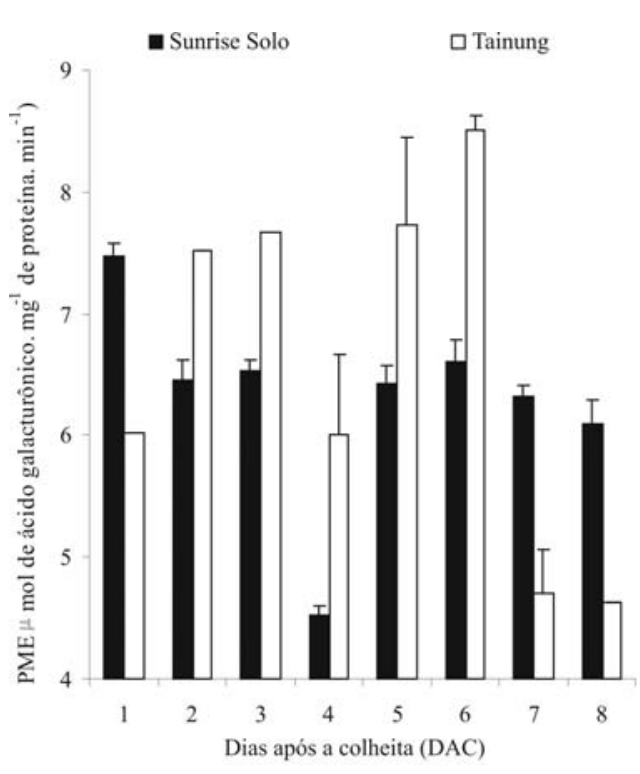

FIGURA 2 - Atividade da pectinametilesterase (PME) na polpa de mamões (Carica papaya L.) cvs. Sunrise Solo e Tainung durante o período de amadurecimento dos frutos. As barras nas colunas representam o erropadrão
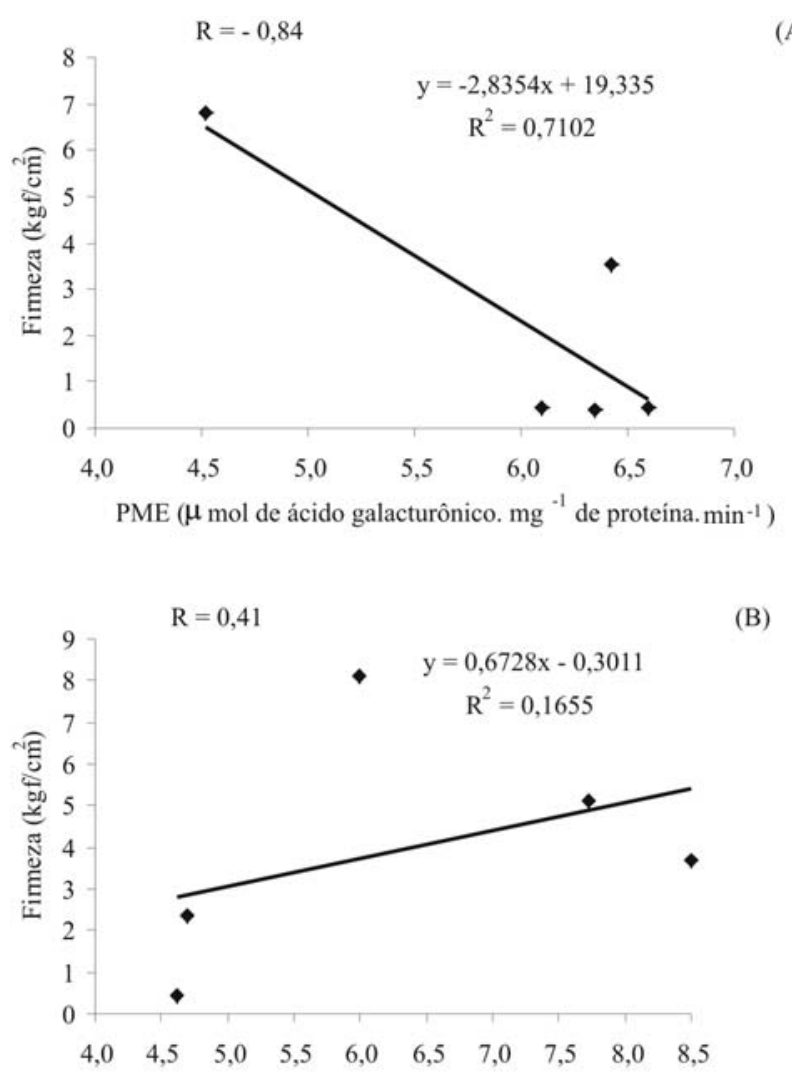

PME $\left(\mu\right.$ mol de ácido galacturônico. $\mathrm{mg}^{-1}$ de proteina. $\left.\min ^{-1}\right)$

FIGURA 3 - Firmeza da polpa de mamões (Carica papaya L.) cvs. Sunrise solo (A) e Tainung (B) em função da atividade da pectinametilesterase (PME). $\mathrm{R}^{2}=$ coeficiente de determinação da regressão e $\mathrm{R}=$ coeficiente de correlação.

\section{AGRADECIMENTOS}

Os autores expressam seus agradecimentos ao Banco do Nordeste, Brapex e Capes, pelo suporte financeiro para a execução do trabalho. Um agradecimento especial ao Dr. José Aires Ventura, do Incaper, pelas sugestões úteis na revisão deste artigo, e ao Mark Paul Culik na revisão do inglês.

\section{REFERÊNCIAS}

ABU-GOUKH, A.; BASHIR, H. A. A. Changes in pectic enzymes and cellulase activity during guava fruit ripening. Food Chemistry, London, v. 83, n. 2. p. 213-218, 2003.

ABU-SARRA, A. F.; ABU-GOUKH, A. A. Changes in pectinesterase, poligalacturonase and cellulose activity during mango fruit ripening. Journal of Horticultural Science, Alexandria, v. 67, n. 4, p. 561-568, 1992.

ALI, Z.M.; CHIN, L.; LAZAN, H.A comparative study on wall degrading enzymes, pectin modifications and softening during ripening of selected tropical fruits. Plant Science, Limerick, v. 167, n. 2, p. 317-327, 2004 a.

ALI, Z.M.; CHIN, L.; MARIMUTHU, M.; LAZAN, H. Low temperature storage and modified atmosphere packaging of carambola fruit and their effects on ripening related texture changes, wall modification and chilling injury symptoms. Postharvest Biology and Technology, Amsterdam, v. 33, n. 2, p. 181-192, 2004b.

BICALHO, U.O.; CHITARRA, A.B.; CHITARRA, M.I.F.; COELHO, A.H.R. Modificações texturais em mamões submetidos à aplicação pós-colheita de cálcio e embalagem de PVC. Ciência e Agrotecnologia, Lavras, v. 24, n. 1, p.136-146, 2000.

CAMARGO, Y.R.; LIMA, L.C.O.; SCALON, S.P.Q.; SIQUEIRA, A.C. Efeito do cálcio sobre o amadurecimento de morangos (fragaria ananassa duch.) cv. campineiro. Ciência e Agrotecnologia, Lavras, v. 24, n. 4, p. 968-972, 2000.

CARVALHO, H.A.; CHITARRA, M.I.F.; CHITARRA, A.B.; CARVALHO, H.S de. Efeito da atmosfera modificada sobre componentes da parede celular da goiaba. Ciência e Agrotecnologia, Lavras, v. 25, n. 3, p. $605-615,2001$.

EVANGELISTA, R.M.; CHITARRA, A.B.; CHITARRA, M.I.F. Influência da aplicação pré-colheita de cálcio na textura e na atividade das enzimas poligalacturonase, pectinametilesterase $\mathrm{e}$ $\beta$-galactosidase de mangas 'Tommy Atkins' armazenadas sob refrigeração. Ciência e Agrotecnologia, Lavras, v.24, n. esp., p.174-181, 2000. Edição Especial

GIOVANNONI, J. Molecular biology of fruit maturation and ripening. Annual Review of plant Physiology and Plant Molecular Biology, Palo Alto, v. 52, p. 725-749, 2001. 
HAGERMAN, A.E.; AUSTIN, P.J. Continuous spectrophotometric assay for plant pectinmethylesterase. Journal of Agricultural and Food Chemistry, Washington, v. 34, n. 3, p. 440-444, 1986.

IBGE (Instituto Brasileiro de Geografia e Estatística). Disponível em: <http://www.ibge.gov.br>. Acesso em: 8 fev. 2005 .

IMSABAI, W.; KETSA, S.; VAN DOORN, W.G. Effect of temperature on softening and the activities of polygalacturonase and pectinesterase in durian fruit. Postharvest Biology and Technology, Amsterdam, v. 26, n. 3, p. 347-351, 2002

JACOMINO, A.P.; KLUGE, R.A.; BRACKMANN, A.; CASTRO, P.R.C. Amadurecimento e senescência de mamão com 1metilciclopropeno. Scientia Agricola, Piracicaba, v. 59, n. 2, p. 303-308, 2002.

LAPPONI, J.C. Estatística usando Excel. São Paulo: Lapponi Treinamento e Editora, 2000. 450p.

LAZAN, H.; SELAMAT, M.K.; ALI, Z.M. $\beta$-galactosidase, polygalacturonase and pectinesterase in differential softening and cell wall modification during papaya fruit ripening. Physiologia Plantarum, Copenhagen, v. 95, n. 1, p. 106-112, 1995.

LIMA, M.A.C.; ALVES, R.E.; FILGUEIRAS, H.A.C. Mudanças relacionadas ao amaciamento da graviola durante a maturação pós-colheita. Pesquisa Agropecuária Brasileira, Brasília, v. 41, n. 12, p. 1707-1713, 2006.
LOURENÇO, E.J.; CATUTANI, A.T. Purification and properties of pectinesterase from papaya. Journal of the Science of Food and Agriculture, London, v. 35, p. 1120-1127, 1984.

LOWRY, O.H.; ROSENBROUGH, N.I.; FAAR, A.L.; RANDALL, R.J. Protein measurement with the Folin phenol reagent. Journal of Biological Chemistry, Baltimore, v. 193, p. 265-275, 1951.

MANRIQUE, G.D.; LAJOLO, F.M. Cell-wall polysaccharide modifications during postharvest ripening of papaya fruit (Carica papaya). Postharvest Biology and Technology, Amsterdam, v. 33 , p. 11-26, 2004.

MWANIKI, M.W.; MATHOOKO, F.M.; MAATSUZAKI.M.; HIWASA, K.; TATEISHI, A.; USHIJIMA, K.; NAKANO, R.; INABA, A.; KUBO, Y. Expression characteristics of seven members of the $\beta$-galactosidase gene family in 'La France' pear (Pyrus communis L.) fruit during growth and their regulation by 1-methylrcyclopropene during postharvest ripening. Postharvest Biology and Technology, Amsterdam, v. 36, p. 253-263, 2005.

OWINO, W.O.; NAKANO, R.; KUBO, Y.; INABA, A. Alterations in cell wall polysaccharides during ripening in distinct anatomical tissue regions of the fig (Ficus carica L.) fruit. Postharvest Biology and Technology, Amsterdam, v. 32, p. 67-77, 2004.

SOUZA, G. Características físicas, químicas e sensoriais do fruto de cinco cultivares de mamoeiro (Carica papaya L.) produzidas em Macaé, RJ. 1998. 87 f. Tese (Mestrado em Produção Vegetal) - Universidade Estadual do Norte Fluminense, Campos dos Goytacazes, 1998. 